\title{
Fabrication of Detectors and Transistors on High-Resistivity Silicon
}

\author{
St:ve Hollind \\ Lawrence Berkeley Laboratory \\ University of California \\ Berkeley, CA 94720
}

LBL- -25520

DE88 016240

\begin{abstract}
A new process for the fabrication of silicon $p$-i-n diode radiation detectors is described. The utilization of backside gettering in the fabrication process results in the actual physical removal of detrimental impurities from critical device regions. This reduces the sensitivity of detector properties to processing variables while yielding low diode reverse-leakage currents. In addition, gettering permits the use of processing temperatures compatible with integrated-circuil fabrication. P-channel MOSFETs and silicon $\mathrm{p}$ - $\mathrm{i}$-n diodes have been fabricated simultaneously on $10 \mathrm{k} \Omega \cdot \mathrm{cm}<100>$ silicon using conventional integrated-circuit processing techniques.
\end{abstract}

\section{Introduction}

The complexity and scale of many new applications for charged particle detectors, notably in highenergy physics, require well-controlled fabrication techniques. Local front-end and readout circuitry is essential for these systems, and monolithic integration of at least part of this circuitry would greatly simplify the readout system and increase performance and reliability [1]. Even on a smaller scale, devices such as the semiconduclor drift chamber [2] would also benefil greatly from integrated front-ends by reducing the circuil capacitance in order to exploit the extremely low capacitance of these detectors. Hence, a modem detector process should offer minimum sensitivity to process-induced contaminants and ileally would be compatible with contemporary integrated-circuit (IC) fabrication techniques. 
However, typical fabrication processes for radiation detectors do not fulfill either of these goals. While in one notable case outstanding results have been achieved [3], the process used is incompatible with conventional IC fabrication and is very sensitive to the temperature at which the implanted dopants are annealed [4]. This is due to the ex'reme sensitivity of detector leakage current to impurities that introduce energy levels near the center of the silicon bandgap [5].

In this work fairly conventional integrated-circuit processing techniques are used to realize lowleakage $p$ - $i$-n diode detectors. The process developed for the detector fabrication relies on the formation of a gettering tayer on the back side of the wafer. By utilizing gettering techniques that actively counteract the presence of harmful impurities in the active volume of the device, the sensitivity of the process to variations in the fabrication environment is greatly reduced. In addition, the use of relatively high processing temperatures is an integral part of the process; this removes a major obstacle to monolithic integration of front-end electronics with the detector. The process described here is fully compatible with conventional IC processing. Data are presented on radiation detectors that demonstrate the effects of getucring and also on p-channel MOSFETs that were fabricated on the same wafer as a furst siep towards monolithically integrated detector-rcadout systems.

\section{Processing Considerations}

A major goal in detector fabrication is shit minimization of the diode reverse-kcakage current, which contributes shot noise and can limit the dynamic range of the input amplifier. High quality floal-zone refined silicon is required in order to achieve the high generation lifetime necessary for low reverseleakage currents. The leakage current of a reverse-biased $\mathrm{p}-\mathrm{n}$ junction is duc to the generation of minority carricrs in the device. These minority carriers can arise from the undepleted neutral region, the depletion region, and the surface [5]. In silicon diodes the leakage current is often dominared by generation in the depletion region. This component of leakage current is greatly enhanced by the presence of impurities that introduce energy levels near the center of the silicon bandgap. Such impurities are often referred wo as lifetime killers since they also decrease the generation lifetime. Typical examples are the transition metals [67]. These are rather ubiquitous contaminants and great care is needed in the fabrication of devices in order 
to achieve low leakage currents.

However, the total elimination of these contaminants has proven to be impractical due to the pervasiveness of such elements and the sensitivity of the leakage current to extremely small concentrations, typically part per billion or less [8-10]. This has led to the development of techniques, collectively known

as gettering, which render ariy lifetime-killing impurities electrically inactive [11]. The basic concept of gettering relies on the fact that at typical integrated-circuit processing temperatures in silicon (approximately 900-1100C) most hamful inpurities have relatively high diffusivities and hence are very mobile [12]. Therefore suitable impurity sinks can be incorporated in electrically inactive regions.

Two general classes of gettering are commonly employed. In "intrinsic" gettering, the bulk of the wafer forms the impurity sink with a relatively thin, defect-free region near the surface where the active devices reside. The technique is often applied to Czochralski-grown substrales and relies on the formation of oxygen precipitates in the bulk of the wafer [11]. While perfeclly adequale for conventional 1C processing, intrinsic gettering is not compatible with thick p-i-n diode delectors, where the depletion region often extends to the backside contact of the wafer. Thus the second class of getuering, "extrinsic" gettering, is utilized in this work. Extrinsic getuering relies on the formwion of a gettering layer on the back side of the wafer, away from the active region of the device, eg. the depletion region of detector diodes. Typical extrinsic geacring techniques include phosphorus doping (8], ion implantation [13], and deposition of thin films such as polysilicon [14] and silicon nitride [15]. Getvering techniques have been applied to detector fabrication, but no details of the actual method used were given [16-17].

\section{Experimental procedures/results}

Figure 1 shows the detector processing sequence used in this work. The rechnique shown has been applied to both $1 \mathrm{k} \Omega \cdot \mathrm{cm}<111>$ and $10 \mathrm{k} \Omega \cdot \mathrm{cm}<100>\mathrm{n}$-type starting substrates with similar results. Initially a layer of polysilicon, in-situ doped with phosphorus, is deposited at $650 \mathrm{C}$ by chemical vapor deposition on the back side of the wafer. This layer, which is approximately $1 \mu \mathrm{m}$ Uhick, serves both as the gettering layer and as the backside contact. The getuering properties of this layer are due to the presence of both the polysilicon and the phosphorus. Polysilicon consists of small grains of single crystal material separated 
by highly disordered regions called grain boundaries. These grain boundaries act as impurity sinks and hence polysilicon itself is an efficient gettering materia $[14,18]$. In addition, phosphorus also getlers impurities by an ion-pairing mechanism [19] and the combination of both methods has been shown to yield synergistic results [20].

After deposition the polysilicon layer is capped by a low-temperature oxide formed by chemical vapor deposition at 450C. This layer minimizes the oxidation of the polysilicon during stbsequent processing. A passivating oxide is then thermally grown, followed by selective removal of the oxide in the areas where boron is desired. For this experiment, the boron was diffused at $900 \mathrm{C}$ from a $\mathrm{B}_{2} \mathrm{O}_{3}$ source in order 10 avoid any crystalline damage at the p-n junction associated with ion implantation. In order to unambiguously determine the effectiveness of the gettering hyer, some of the wafers received the backside polysilicon gettering on one half of the wafer only, while the other half received implantation of arsenic to form the back contact. After implantation the wafers were annealed at $900 \mathrm{C}$ for fifteen minutes in oxygen followed by a two hour anneal at the same temperature in nitrogen. Conventional aluminum metallization followed by a $400 \mathrm{C} / 450 \mathrm{C}(<100>/<111>)$ anneal in forming ges (80\% nitrogen, 20\% hydrogen) completes the processing.

The detector diodes used in this work were circular in area with a $1 \mathrm{~mm}$ radius. In addition, the diodes were surounded by a circular gaard ring consisting of a $\mathrm{p}^{+}$region consacted by metallization. The inner radius of the guard ring measured from the cenver of the diode was $1.1 \mathrm{~mm}$, and the outer radius was $1.4 \mathrm{~mm}$. For the diode current-voliage measurements, the bias voluge was applied to the substrate with the top conlact and guard ning grounded.

Figure 2 compares the reverse-leatage curnents of gettered and ungettercd devices from the same wafer $(<100>10 \mathrm{k} \Omega \cdot \mathrm{cm})$. The geuered sample exhibits a substantially reduced leakage current relative to the sample that did not receive the getlering. The current is reduced by a factor of nearly 400 at low voltages and even more at higher voltages where the ungettered sample exhibits a soft breakdown characterisic. The leakage current density a $100 \mathrm{~V}$, which corresponds to a fully depleted detector $(=250 \mu \mathrm{m}$ depletion region thickness), is on the order of 1-2 $\mathrm{nA} / \mathrm{cm}^{2}$, which compares very favorably with the result of Kemtiver [3]. However, the Kemmer process limits the processing temperatures to $600 \mathrm{C}$ afler the initial 
oxidation. This restriction is necessary in order to maintain low leakage currents for that process, and in fact an attempt to incorporale higher anneal temperatures into a similar process has been reported to increase the leakage current significantly, eg. $420 \mathrm{nA}_{\mathrm{c}} \mathrm{cm}^{2}$ per $100 \mu \mathrm{m}$ depletion width after annealing at $900 \mathrm{C}$ [4]. In contrast, the devices shown in Figure 2 have undergone approximatcly 3 hours at $900 \mathrm{C}$ after the initial oxide was grown, while maintaining low keskage currents. Thus this process avoids the major drawbacks of the Kemmer process, namely the high sheet resistance of the implanted layers and resulting incompatibility with monolithic integration of active devices.

The curnent of the gettered device in Figure 2 is relatively insensitive to voltage, which implies that the current is limited by either diffusion of minarity carriers from the undepleted regions of the diode, or from surface leakage currents, but not from generation in the depietion region. The bulk generation current is expected to increase with the volume of the depletion region, which is in tum bias-voltage dependent [5].

Similar resulis were observed for the <111> substrales. However, a significant surface component of leakage current is observed on the <111> substrates (on the order of 3-12 $\mathrm{nA} / \mathrm{cm}^{2}$ ) [21]. This current arises from electrically active states at the silicon-silicon dioxide interface. It can be suppressed by proper biasing of a metal-oxide-semiconductor (MOS) capacitor located between the diode and guard ring, similar to a gatal-diode structure [5]. Once the surface kelkage current is suppressed, the gettered devices achieve leakage currents on the order of $1 \mathrm{nA} / \mathrm{cm}^{2}$ as shown in Figure 3. The higher surface current for the <111> substrates is consistent with the higher density of surfuce steves on oxidized <111> substrates as compared to the $<100>$ orientation [22].

A significant aspect of the getuering process is the fact that the diodes were fabricated at typical integated-circuit processing kempenaures. Thus monolithic integruion of detectors and active devices can be investigated with the use of a process employing gettering, and MOS devices on high-resistivity silicon have been reported [23]. In onder to pursue this further, polysilicon-gate p-channel MOS transistors were fabricated simultaneously with detector diodes on high-resistivity silicon. The only additional steps required for the transistor fabrication consisted of the growth of a $36.5 \mathrm{~nm}$ gate oxide in steam at $800 \mathrm{C}$ followed by the chemical vepor deposition of polysilicon at $610 \mathrm{C}$ to form the gate of the transistor. The source/drain regions of the transistor are self-aligned to the gate to minimize the gate to drain overlap 
capacilance [22].

In order to determine directly the effect of this additional processing on the delector properties, detector diodes were fabricaled on the same substraces. This was accomplished by using a mask aligner which steps nine separate $1 \mathrm{~cm}^{2}$ ficlds. Five of these fields were devoted to the transistor array and the other four contained the diodes described previously. The polysilicon and gate oxide were completcly removed from the diode fiekds prior to boron doping, which simultancously formed the source/drain regions of the transistors and the top contact of the diode.

Figure 4 shows typical ouxput current-voltage characteristics of a p-channel MOSFET fabricated on $10 \mathrm{k} \Omega \cdot \mathrm{cm}$ silicon. The channel width and length for this device are $26 \mu \mathrm{m}$ and $5 \mu \mathrm{m}$, respectively. Due to the high-resistivity malerial the devices behave normally even with a large bias (100V in Figure $4 \mathrm{~b}$ ) applied to the substrate as has been reported earlier [23]. The change in device threshold voltuge due to the substrate bias is proportional to the square rool of substrate doping [22] end hence is very snall in this case.

The I-V characteristic of a p-i-n diode fabricaled on the same water is shown in Figure 5. The leakage current is on the order of $1-3 \mathrm{nA} / \mathrm{cm}^{2}$, comparable to the resulls shown in Figures 2 and 3 . Hence no significan degradation in the detector diode properties result from the additional processing necessary wo fabricate p-chanael transistors. The fact that the devices were processed al 900C for nearly 3 hours while maintaining low kakage current is significant and ofTers the prospect that CMOS or JFET circuits can be integrated directly with the delector on high-resistivity silicon.

Figure 6 shows the response of a detoctor fabricated on <100s silicon 10 an Americium 241 source [24]. The ful] width at hal[ maximum for the $59.4 \mathrm{KeV}$ gamms ray is spproximalely 1.7-1.8 KeV yielding an energy resolution of approximately $3 \%$, which is limiled by the noise of the signal-processing electronies. 


\section{Conclusion}

A silicon detector process has been developed that is compatible with standard IC processing. Extrinsic gettering of lifetime-killing impuritics yields leakage current densities in the range $1-3 \mathrm{nA} / \mathrm{cm}^{2}$ at depletion region thicknesses of $250-300 \mu \mathrm{m}$. Gettering allows processing temperatures consistent with Iypical IC fabrication, and reduces the sensitivity of the process to detrimental impurities. The arditional processing necessary to fabricale p-channel MOSFETs did not significantly degrade the deteclor leakage curnen. Hence, the effective use of geucring provides a path to integrating readout electronics on the same substrate with the detector diode with potentially high fabrication yields. It remains to be seen if variations of this technique can be applied to devices which require junction formation on both sides of the wafer such as the silicon drift chamber [2]. Horvever, good gettering results have been reported using a pattemed silicon nitride film [25] thus offering hope that drift chambers and other two-sided devices could also benefit from gettering.

\section{Acknowledgements}

Helpful conversations with D.R. Nygren and H.G. Spieler of the Lawrence Berkeley Laboratory and L. Bosisio of IN.F.N (Pisa, Italy) are gratcfully acknowledged. Special thanks are duc J.T. Walion of the Lawrence Berkeley Laboratory for the measurement of the detector response to Americium 241. This Fenarch was sponsored by the U.S. Department of Energy under contract number DE-AC03-76SF00098. 


\section{References}

[1] G. Zimmer, "Technology for the computible integreion of silicon devecton with readout electronics," Nucl. Instr. Meth., vol. 226, p. 175, 1984.

[2] E. Gatti, P. Rehak, and J.T. Walion, "Sijicon drift chambers- first resulte and optimum processing of signais," Nucl. Instr. Meth., vol. 226, p. 129, 1984.

[3] J. Kemmer, "Improvement of detector fabrication by the planar process," Nucl. Instr. Meth., vol. 226, p. 89, 1984.

[4] PJ. Van Wijnen and W.R. Th. Ten Kete, "Charge carrier lifetime mesurements on high purity silicon," Nucl. Instr. Meth., vol. A253, p. 351, 1987.

[5] A.S. Grove, "Physics and Tetinology of Semiconductor Devices," John Wiley and Sons, Inc., 1967.

[6] E.R. Weber, "Transition metals in silicon," Appl. Phys. A, vol. 30, p. 1, 1983.

[7] S.M. Sze, "Physics of Serniconductor Devices," 2nd Edition, p. 21, John Wiley and Sons, Inc., 1981.

[8] A. Goetzberger and W. Shockley, "Metal precipitutes in silicon p-n junztions," J. Appl. Phys., vol. 31, no. 10, p. 1821, Oct. 1960.

[9] KJ. Rawlings, "The generation lifetime in high aesistivity silicen," Nucl. Instr. Meth., vol. A260, p. $201,1987$.

[10] P. Eichinger, "Chancierization and andysis of deteclor muerials and processes," Nucl. Instr. Meth., vol. A 253, p. 313, 1987.

[11] A recent review peper on getering is T.F. Seided, "Genering in silicon," in Materials Issues in Silicon Integraced Circuit Precesting, Mat. Res. Soc. Symp. Proc., vol. 71, M. Witumer, J. Stimmell, M. Strathman (edicors),, MRS, Piusburgh, PA, p. 3, 1986.

[12] S.M. Sze, "Filysics of Semiconóuchor Devicex," 2nd Edition, p. 68, John Wiley and Sons, Inc., 1981.

[13] T.M. Buck, K.A. Picke, J.M. Ponte, and C.-M. Hsich, "Gettering rales of various fast-diffusing mets impurities at ion-demaged layers on silicon," Appl. Phys, Lell, vol. 21, no. 10, Nov. 1972. 
[14] S.M. Hu, U.S. Patent 4,053,335 (Oct. 11, 1977 ).

[15] P.M. Pctroff, G.A. Rozgonyi, and T.T. Sheng. "Eimination of process-induced stacking faults by preoxidation gettering of Si wafers. II. $\mathrm{Si}_{3} \mathrm{~N}_{4}$ process," I. Electrochem. Soc., vol. 123, no. 4, p. 565, April 1976.

[16] TE. Hansen, "Silicon detectors for the UV. and blue spectmal regions with possible use as particle delectors," Nucl. Instr. Meth., vol, A235, p. 249, 1985.

[17] M. Caccia et al, "A Si strip detector with integraved coupling capacilors," Nucl. Instr. Meth., vol. A260, p. 124, 1987.

[18] S.M. Hu, "Defects and device processing: achievements and limitations," in Semiconductor Silicon/1986, Proc. Sth Int. Symp. on Silicon Merer. Sci. and Tech., vol. 86-4. H.R. Huff, T. Abe, B. Kolbesen (cditors), The Electrochem. Soc., Pennington, NJ, p. 722, 1986.

[19] D. Lecrosnier, J. Paugam, F. Richou, and G. Pelous, "Influence o: phoaphorus-induced point defects on a gold-gettering mechenian in silicon," J. Appl. Fhyl., voi. 51, no. 2, p. 1036, Feb. 1980.

[20] D.E. Hill, "Gettering of gold in silicon waters using various beckside gettering wechniques," in Proc. os the Symp. on Defects in Silicon, vol. 83-9, W.M. Bullis and L.C. Kimerling (editors), The Elocurochem. Soc., Pennington, NJ, p. 433, 1983.

[21] S. Kolland, to be published

[22] R.S. Mulles and T.I. Kamins, "Device electronics for integned circuits," 2nd Edition, John Wiley and Sons, Inc., 1986.

[23] G. Vansuraclen, I. DeBusschere, C. Clacys and G. Declerck, "New concepts for inlegrated solid staic delector electronics," presented at the London Conference on Position-Sensitive Delectors, University Colkge, London, Sept. 7-11, 1987.

[24] Measurement courtesy of J.T. Walion, Lawrence Berkeley Labaratory.

[25] Y. Mada, "Defect eliminating method using $\mathrm{Si}_{3} \mathrm{~N}_{4}$ film petserns," Jap. J. Appl. Psyss., vol. 2I, no. 11, p. L683, Nov. 1982. 


\section{Figure coptions}

Fig 1 The fabrication process used in this work.

Fig 2 The detector diode reverse-leakage current for a device with backside gettering compared to one without. The devices were fabricated on $10 \mathrm{k \Omega} \cdot \mathrm{cm}<100>$ substrates, and both devices are from the same wafer.

Fig 3 The detector diode reverse-leakage current for a device with beckside gettering compared to one without. The devices were fabricated on $1 \mathrm{k} \Omega \cdot \mathrm{cm}<111>$ substrates, and both devices are from the same wafer. For the getcered device the surface kakage current has been suppressed by biasing an MOS capacitor located between the diode and gund ring a $-5 \mathrm{~V}$.

Fig 4 Current-voltage characteristics of a p-channel MOSFET fabricaled on $10 \mathrm{k} \Omega \cdot \mathrm{cm}$ silicon. The transistor gale oxide thickness is $36.5 \mathrm{~nm}$, and the channel width to kngth ratio is $26 \mu \mathrm{m} / 5 \mu \mathrm{m}$.
(a) Zero volts subatrace bins.
(b) 100 volss suberme bias.

Fig 5 Detector diode reverse-leakage current of a device fabricaled on the same substrate with p-channel MOSFETs.

Fig 6 The response of a decector fabricated on <100> silicon to an Americium 241 source. The peak at lower channel numbers is the delector response to the $59.4 \mathrm{KeV}$ gamma ray whereas the peak at higher chanel numbers correquonds to a voluge pulser applied directly to the input of the preamplifier. The full width a half maximum is epproximately the same for both implying that the devetor respone is dominmed by the noise in the aignal processing electronics. The diode bias was $30 \mathrm{~V}$ 
and the integration time was 0.8 microseconds. The counting period was approximately eight hours and the measurcments were performed ai room temperature. The sersitivity is approximately 0.026 $\mathrm{KeV}$ per channel. 
$\mathrm{n}^{-} \mathrm{Si}$

$\mathrm{n}^{+}$polysilicon

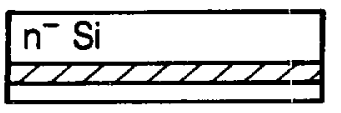

$\mathrm{n}^{+}$polysilicon $\mathrm{SiO}_{2}$

(1) Deposition of in situ-doped polysilicon on the backside

(2) Deposition of silicon dioxide on the backside

(3) Thermal oxidation

(4) Photolithography and etching of the silicon dioxide

(5) Boron doping and removal of backside oxide

(6) Aluminum metallization

XBL 883-10153 


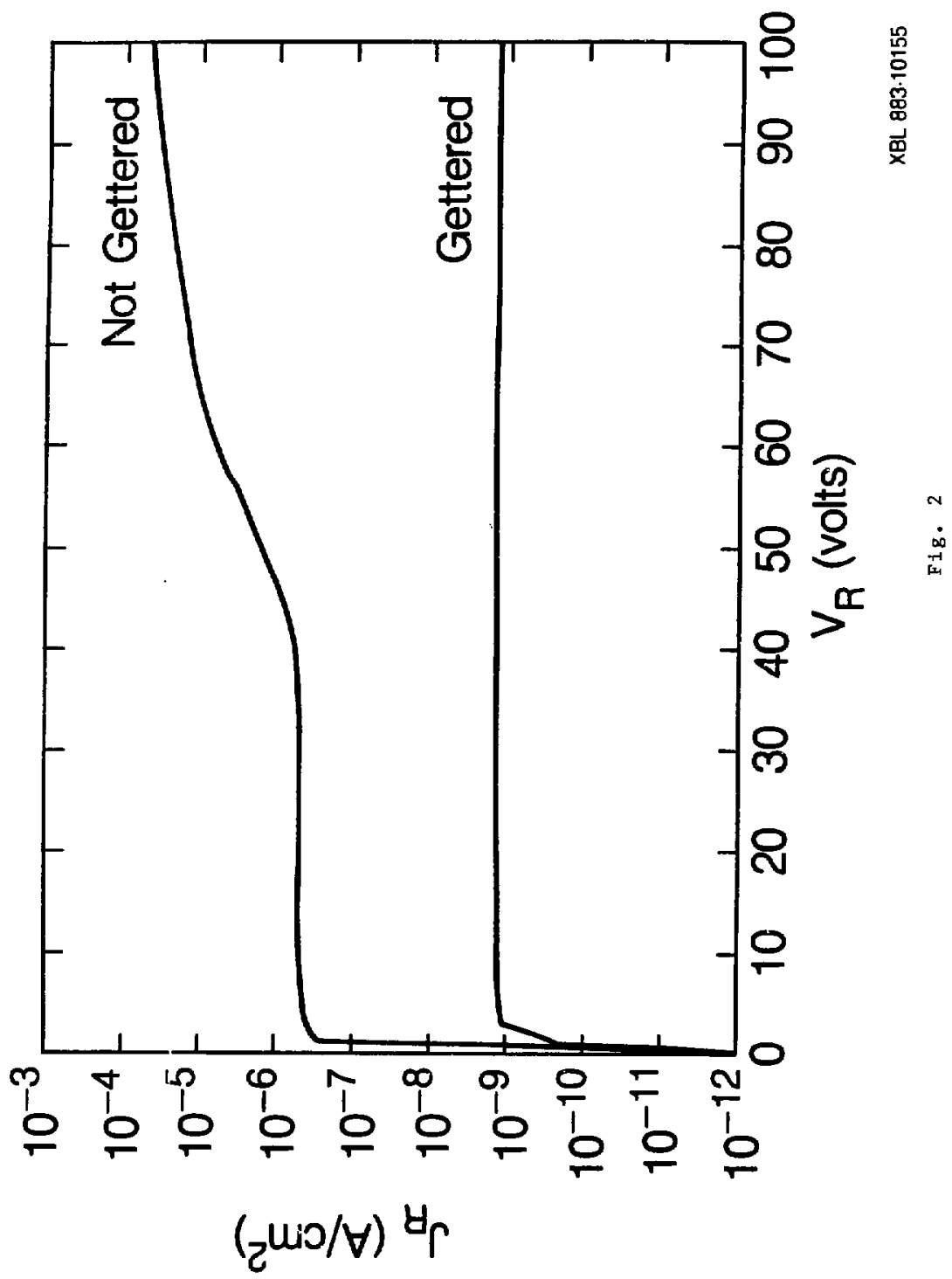




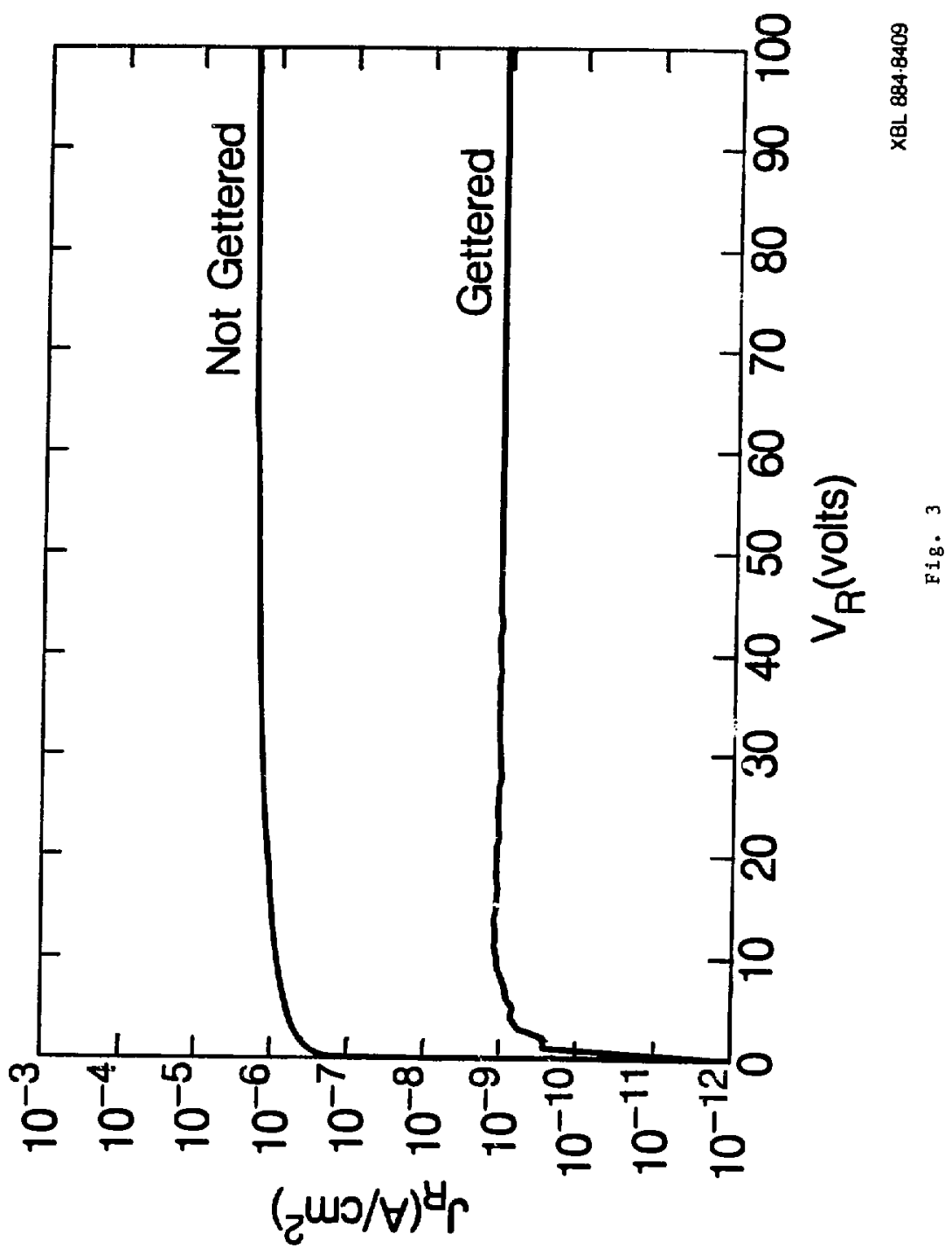


a)

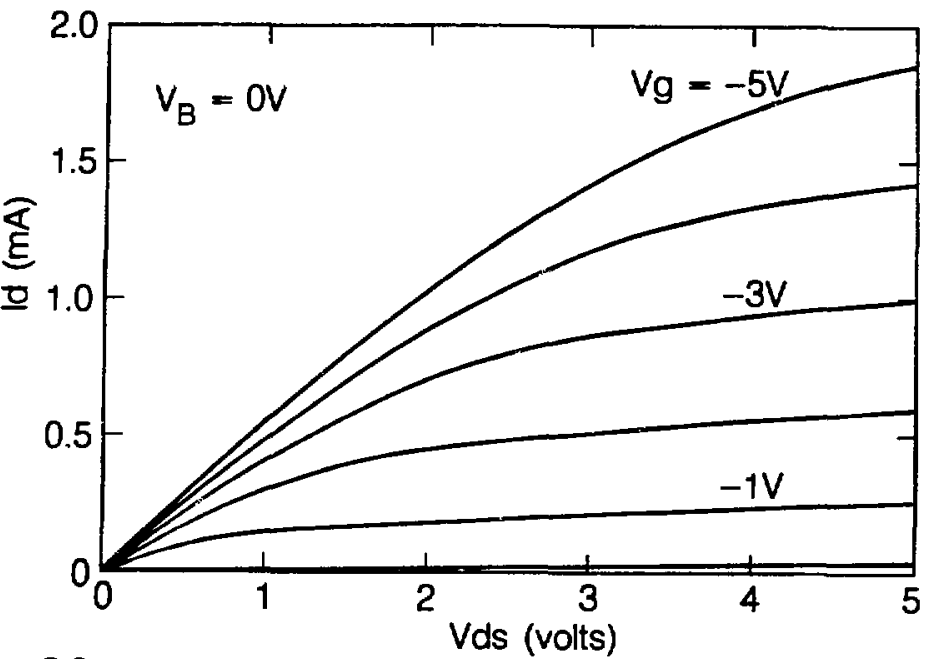

b)

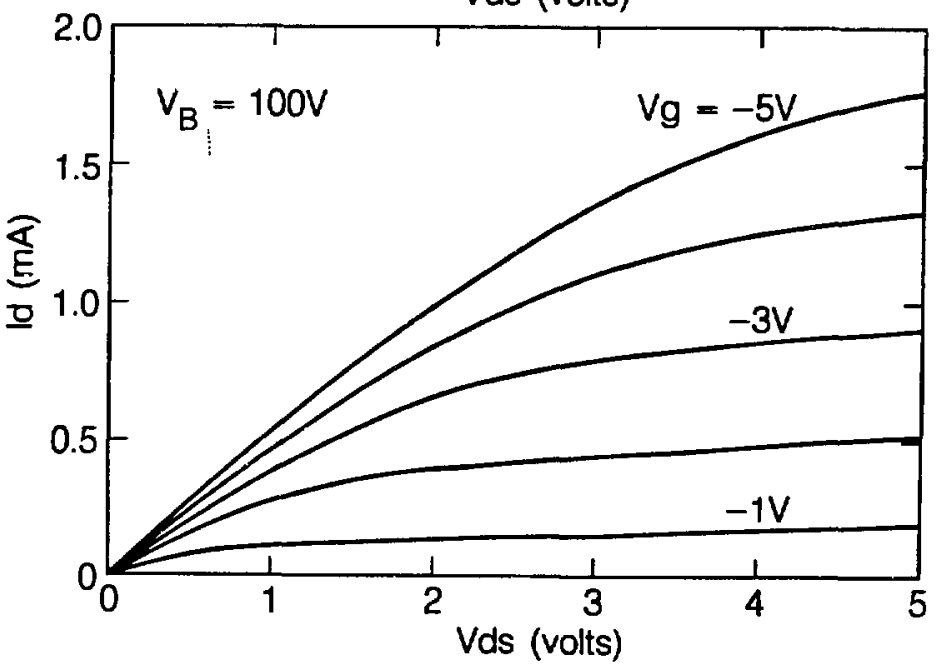




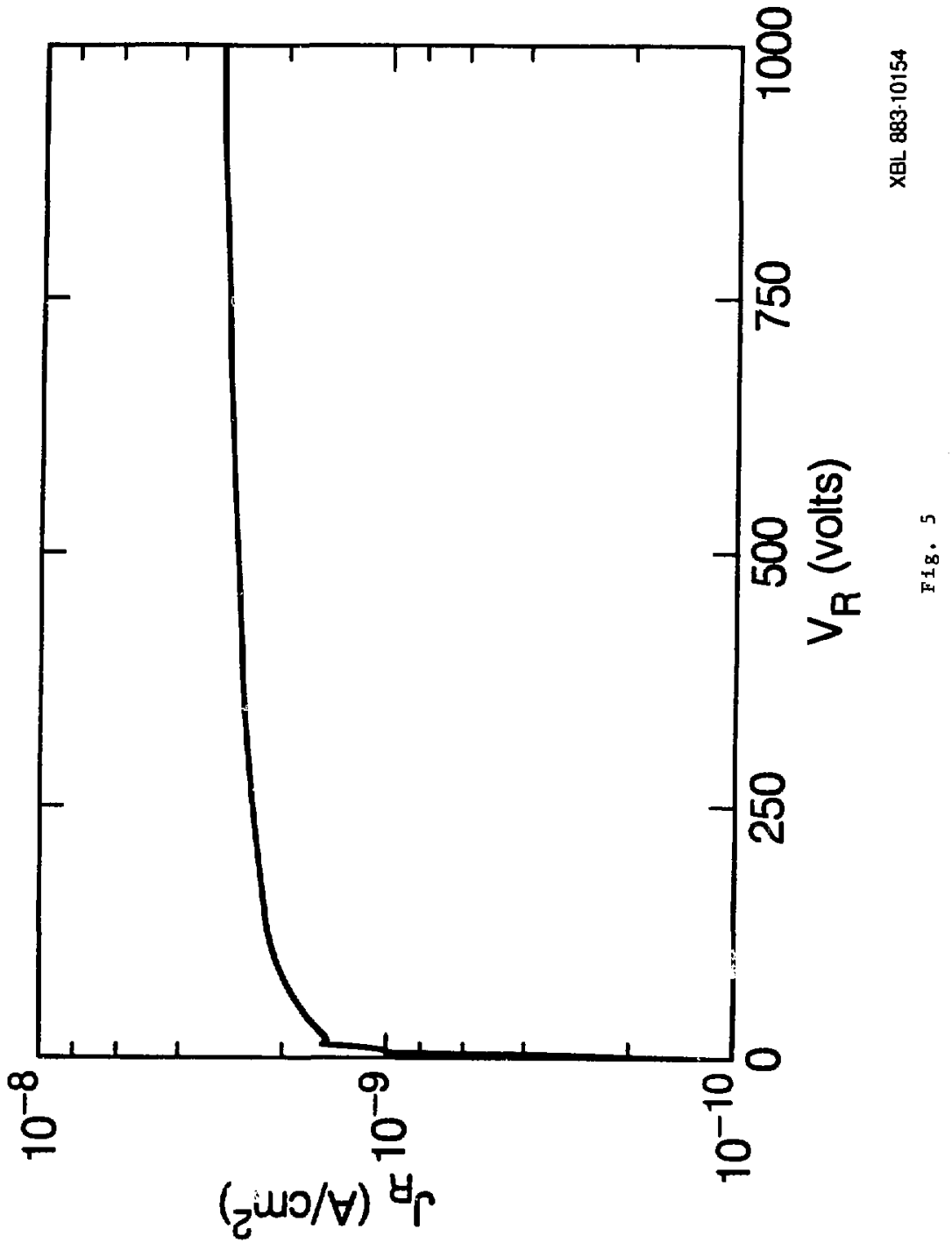




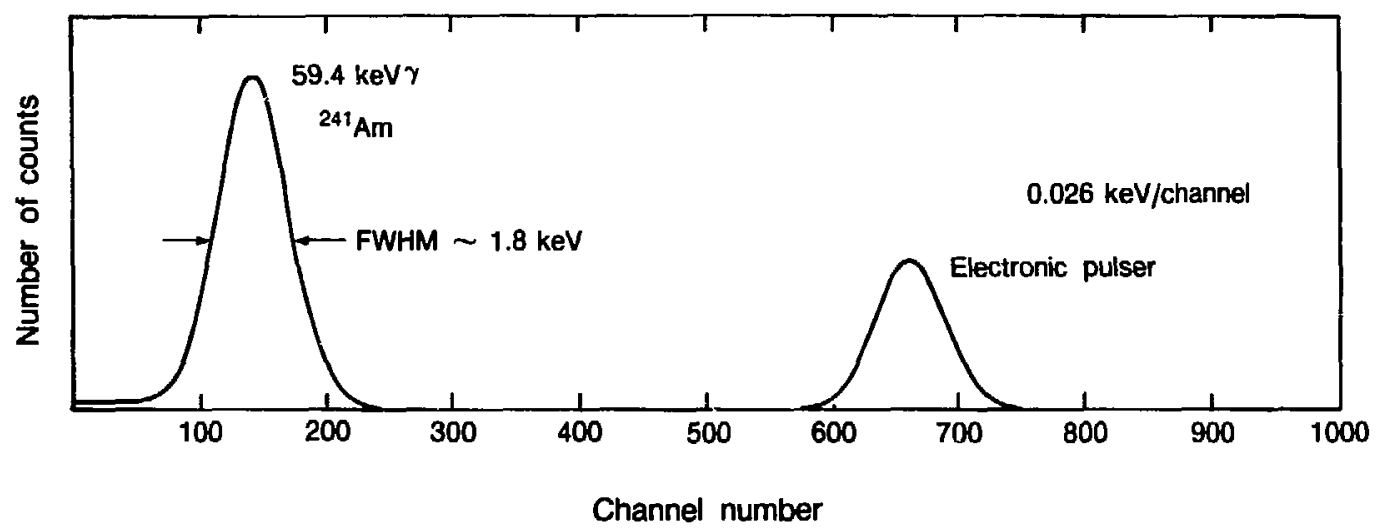

XBL 806.9693

F1g. 6 